\title{
Flavonoids in Passiflora incarnata L. Dry Extract of Russian Origin
}

\author{
Guseinov MD', Bobkova NV², Svistunov AA², Tarasov VV², Bokov DO ${ }^{2,3, *}$, Sergunova EV ${ }^{2}$, Kovaleva TYu
}

Guseinov MD', Bobkova NV² Svistunov AA', Tarasov VV ${ }^{2}$, Bokov DO $2,3, *$, Sergunova EV', Kovaleva TYu²

'Medical College named after Bashlarov, Amet Khan Sultan Ave., 10th km., 367915 Makhachkala, Republic of Dagestan, RUSSIA.

${ }^{2}$ Sechenov First Moscow State Medical University, 8 Trubetskaya St., bldg. 2 , 119991, RUSSIA.

${ }^{3}$ Federal Research Center for Nutrition, Biotechnology and Food Safety, 2/14,

Ustyinsky pr., Moscow, 109240, RUSSIA.

\section{Correspondence}

\section{Bokov DO}

Sechenov First Moscow State Medical

University, 8 Trubetskaya St., bldg. 2 119991, RUSSIA.

Federal Research Center for Nutrition

Biotechnology and Food Safety, 2/14,

Ustyinsky pr., Moscow, 109240, RUSSIA.

E-mail: fmmsu@mail.ru

History

- Submission Date: 16-07-2019;

- Review completed: 19-07-2019;

- Accepted Date: 24-07-2019.

DOI : 10.5530/pj.2019.11.178

Article Available online

http://www.phcogj.com/v11/i5

\section{Copyright}

(C) 2019 Phcogi.Com. This is an openaccess article distributed under the term of the Creative Commons Attribution 4.0 International license.

\section{ABSTRACT}

Background: Flavonoids are one of the main classes of biologically active substances providing the pharmacotherapeutic effect of passionflower (Passiflora incarnata L.) preparations. In this article studies on the standardization of Passiflora incarnata L. dry extract (PDE) by flavonoids are presented. The aim of this work was to study the composition and content of flavonoids in PDE with the help of precise modern physicochemical methods.

Materials and methods: PDE was prepared from crude herbal drug - $P$. incarnata herb of Russian origin. Reverse phase HPLC-UV analysis was performed with Agilent 1100 liquid chromatograph. Chromatographic column was Atlantis $C_{18}(250 \mathrm{~mm} \times 4.6 \mathrm{~mm} \times 5 \mu \mathrm{m})$; analytical wavelength $-350 \mathrm{~nm}$; mobile phase $-0.01 \%$ formic acid solution and methanol: acetonitrile (25:75); column temperature $-35^{\circ} \mathrm{C}$; analysis time $-90 \mathrm{~min}$; flow rate of the mobile phase $-0.8 \mathrm{ml} / \mathrm{min}$ in gradient elution mode. Commercially available samples of flavonoids were used for identification and quantitative determination.

Results: 20 compounds of flavonoid structure are presented in the PDE. 9 flavonoid compounds have been identified, they are: isovitexin, vitexin, rutoside, hyperoside, luteolin, kaempferol kaempferitrin, orientin, and isoorientin. The content of vitexin is $0,867 \pm 0,011 \%$, the total flavonoids content in terms of vitexin is $3,762 \pm 0,049 \%$.

Conclusion: The obtained data will be used to create regulatory documentation for drugs based on PDE.

Key words: Passiflora incarnata, Dry extract, Standardization, Flavonoids.

\section{INTRODUCTION}

Passiflora incarnata L. or purple passionflower (Figure 1) - a perennial herbaceous tropical plant of the family Passionflower (Passifloraceae Juss. Ex Roussel). The P. incarnata homeland is tropical Brazil, Bermuda, as well as subtropical regions of North America. ${ }^{1} P$. incarnata is introduced in Kobuleti along the Black Sea coast of the Caucasus in Russia, where industrial plant areas are located. ${ }^{2}$

Currently, alternative treatment of patients with herbal drugs (including passionflower) with anxiety disorders remains extremely urgent. P. incarnata herb contains about $0.04 \% \beta$-carboline alkaloids - harmine, harmane, harmalol. ${ }^{3}$ Also $P$. incarnata herb includes various groups of biologically active substances (BAS): chlorophyll and pectin substances, saponins, vitamins, ${ }^{4}$ oxycoumarins; ${ }^{5}$ a complex of flavonoids (vitexin, quercetin, luteolin, apigenin), which has sedative activity; coumarins, quinones. ${ }^{6}$

P. incarnata herb contains a wide variety of flavonoid glycosides. The presence of vicenin-2, schaftoside, isoschaftoside, orientin, isoorientin2 "-O- $\beta$-glucopyranoside, isoorientin, isovitexin2 "-O- $\beta$-glucopyranoside, swertisin, isovitexin, vitexin were established by group of Italian researchers. ${ }^{7}$ A team of researchers from Austria and Germany identified flavone C-glycoside isoscoparin-2"-O-glucoside in the $P$. incarnata herb. ${ }^{8}$ Also 2-O-Glucosyl-6-C-glucosylapigenin, 6 - $\beta$-D-glucopyranosyl-8- $\beta$-D-ribopyranosyl apigenin were isolated from $P$. incarnata herb. ${ }^{9,10}$
In the extract of $P$. incarnata, the following hydroxycinnamic acids are found: a derivative of caffeic acid, p-coumaric acid glycoside and chlorogenic acid. Flavonoids are present in the form of apigenin, kaempferol, quercetin glycosides. ${ }^{11}$

The $P$. incarnata crude herbal drugs (CHD) are included in the European Pharmacopoeia, ${ }^{12}$ the State Pharmacopoeias of Germany, ${ }^{13}$ France $^{14}$ and the United Kingdom, ${ }^{15}$ the British herbal pharmacopoeia. ${ }^{16}$ In Russia there is pharmacopoeial monograph 42-2784-91 regulating the quality of the crushed herb of passionflower. ${ }^{17}$

PDE (Figure 2) in combination with extracts of other CHD is a part of domestic and foreign drugs "Stressoff Forte", "Stressoff" (JSC "Vifehtech", Russia), "Novopassit” (Czech Republic, Israel), used as sedatives; ${ }^{18}$ and as part of complex homeopathic remedies for the treatment of alcohol dependence. ${ }^{19}$ Passiflora extracts have a confirmed anxiolytic activity. ${ }^{20}$ In an experiment in mice, it was found that, in addition to the neuroprotective effect, a decrease in the level of neuropathic pain is characteristic for passionflower. ${ }^{21}$ Base antinociceptive mechanisms are carried out due to the effect on opioid, GABA receptors. Sedative action is provided through GABA-ergic mechanisms, due to which a dosedependent effect is realized. ${ }^{21}$ Flavonoids can possess antiepileptic properties. ${ }^{22}$

Since flavonoids are one of the main classes of BAS providing the pharmacotherapeutic effect of passiflora preparations, it was necessary to determine their qualitative composition and content with the 


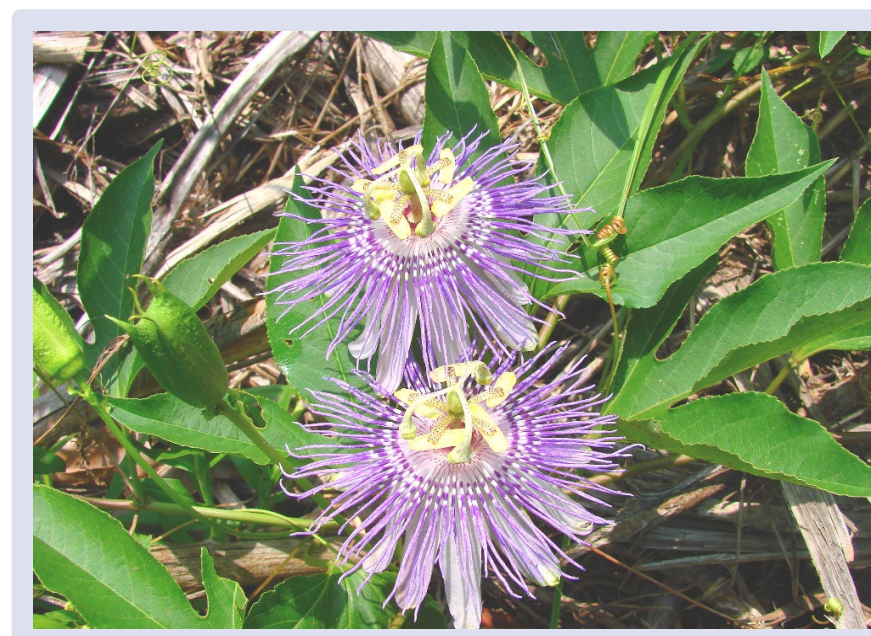

Figure 1: Purple passionflower (Passiflora incarnata L.).

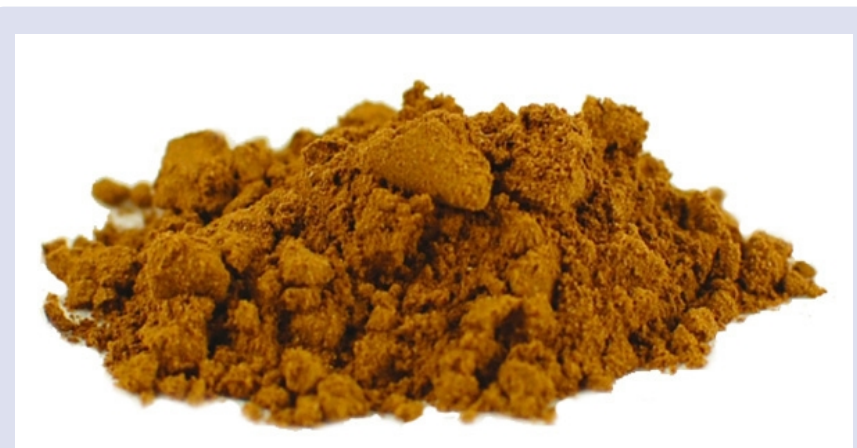

Figure 2: Passiflora incarnata dry extract.

use of precise modern physicochemical methods, one of which is HPLC-UV (DAD) ${ }^{23}$

The purpose of this work is to study the composition and content of flavonoids in P. incarnata herb dry extract.

\section{MATERIAL AND METHODS}

P. incarnata herb dry extract (70\% ethanol, ratio of CHD and extragent is 1: 2) was investigated. The P. incarnata herb was harvested during the flowering phase - the beginning of fruiting in the Krasnodar Territory (Sochi, Dagomys settlement) in 2016. P. incarnata plants have been identified by Bokov Dmitry Olegovich, associate professor of Pharmaceutical Natural Sciences Department, voucher specimens were deposited at the Pharmaceutical Natural Sciences Department Herbarium.

Commercially available samples of individual substances: luteolin7-O-glucoside (Sigma-Aldrich, CAS No. 5373-11-5, $\geq 98 \%$ ), vitexin (Sigma-Aldrich, CAS No. 3681-93-4, $\geq 95 \%$ ), isovitexin (SigmaAldrich, CAS No. 38953-85-4, $\geq 95 \%$ ), rutin trihydrate (SigmaAldrich, CAS No. 250249-75-3, $\geq 94 \%$ ), luteolin (Sigma-Aldrich, CAS No. 491-70 -3, $\geq 97 \%$ ), hyperoside (Sigma-Aldrich, CAS No. 482-36-0, $\geq 97 \%$ ), kaempferol (Sigma-Aldrich, CAS No. 520-18-3, $\geq 99.0$ ) were used as standard samples (SS).

Investigations of the composition and content of individual flavonoids in PDE were carried out on an Agilent 1100 liquid chromatograph. The chromatograph is equipped with a twosolvent feed and degassing system, a diode array detector, a column thermostat, and an autosampler. Data collection, processing of chromatograms and absorption spectra were obtained with the help of Agilent ChemStation. Atlantis $\mathrm{C}_{18}$ chromatographic column
(WATERS, USA) was used for separation of flavonoid compounds. It is reversed-phase HPLC (250 $\mathrm{mm}$ in length and $4.6 \mathrm{~mm}$ in internal diameter, with a particle size of $5 \mu \mathrm{m}$, filled with silica gel chemically bonded to octadecylsilane). The wavelength of the detection corresponded to the local maxima (peaks), it was selected after recording the absorption spectra at wavelengths of 190-700 nm. 350 $\mathrm{nm}$ was the analytical wavelength. A solvent system of $0.01 \%$ formic acid solution and methanol: acetonitrile (25:75) (for HPLC, PanReac AppliChem) was used as the mobile phase; column temperature was $35^{\circ} \mathrm{C}$; analysis was lasting for $90 \mathrm{~min}$. The flow rate of the mobile phase is $0.8 \mathrm{ml} / \mathrm{min}$. The maximum pressure is $400 \mathrm{bar}$. The volume of the injected sample is $10 \mu$ l. The gradient elution scheme is shown in Table 1.

The PDE preparation for the HPLC analysis was carried out in accordance with the methodology presented below.

\section{Method of PDE preparation for the flavonoid analysis}

To determine the flavonoid content in PDE, the $50 \mathrm{mg}$ (accurately weighed quantity) of the extract was dissolved in $2 \mathrm{ml}$ of the solvent ( $40 \%$ ethanol), placed in centrifuge tubes and centrifuged for 15 minutes at a rate of 4,500 rpm. The supernatant was placed in a vial for chromatography.

Statistical data processing was performed with the help of Microsoft Office Excel 2010.

\section{RESULTS AND DISCUSSION}

The affiliation of compounds to the class of flavonoids was evaluated on the basis of absorption spectra. The absorption maxima at 250, $350 \pm 5$ $\mathrm{nm}$ should be observed (as for UV-spectrum of vitexin) to confirm the flavonoid nature (Figure 3).

Calculation of flavonoids content (\%) in the PDE was carried out in terms of vitexin according to the formula:

$X=\frac{S_{1} \cdot a_{2} \cdot R}{S_{2} \cdot a_{1}}$

where $S_{1}$ - sum of the flavonoid peaks areas on the chromatogram of the test sample; $S_{2}$ - peak area of vitexin on the chromatogram of standard sample solution; $\mathrm{a}_{1}$ - sample mass of PDE, $\mathrm{g} ; \mathrm{a}_{1}$ - mass of vitexin in a standard sample solution, $\mathrm{g} ; \mathrm{R}$ - dilution.

Based on the published $\operatorname{data}^{24}$ and taking into account the

Table 1: Scheme of flavonoids gradient elution.

\begin{tabular}{|c|c|c|}
\hline Time & Methanol: acetonitrile (25:75) & $0.01 \%$ formic acid solution \\
\hline 0 & 0 & 100 \\
\hline 80 & 80 & 20 \\
\hline 85 & 0 & 100 \\
\hline 90 & 0 & 100 \\
\hline
\end{tabular}

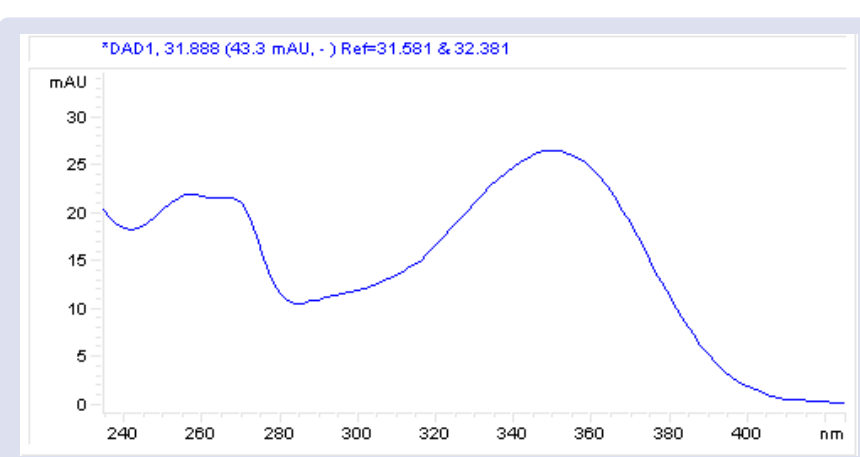

Figure 3: UV absorption spectrum of vitexin (240-400 nm). 
chromatographic characteristics of compounds with retention times $\mathrm{Rt}=46.3 \mathrm{~min}, \mathrm{Rt}=55.9 \mathrm{~min}, \mathrm{Rt}=60.99$, it can be assumed that they are probably kaempheritrin, orientin and iso-orientin, respectively. Nevertheless, the data of the MS analysis can reliably confirm these results. Chromatogram obtained in HPLC-UV analysis is presented at Figure 4.

Vitexin is one of the main flavonoids of PDE according to the Table 2.

The results of the flavonoids determination are given in Table 3.

The results of this analysis are consistent with data obtained by other researchers studied $P$. incarnata. ${ }^{24-27}$ The predominant flavonoids are vitexin and orientin. Literature sources display the direct correlation

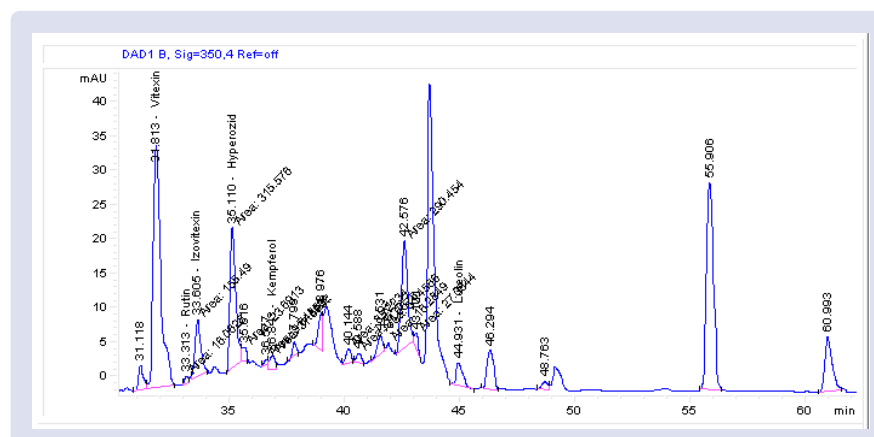

Figure 4: HPLC-UV chromatogram of PDE flavonoids.

Table 2: Characteristics of peaks in the HPLC-UV chromatogram of PDE flavonoids.

\begin{tabular}{|c|c|c|c|c|c|}
\hline No & $\begin{array}{l}\text { Retention } \\
\text { time (min) }\end{array}$ & $\begin{array}{l}\text { Identified } \\
\text { compound }\end{array}$ & Peak area & $\begin{array}{l}\% \text { of total } \\
\text { peak area }\end{array}$ & $\begin{array}{l}\text { Symmetry } \\
\text { coefficient }\end{array}$ \\
\hline & 31,118 & & 59,2 & 1,718 & 0,49 \\
\hline & 31,813 & vitexin & 794,4 & 23,060 & 0,592 \\
\hline & 33,113 & rutoside & 16,1 & 0,467 & 0,584 \\
\hline & 33,605 & isovitexin & 155,5 & 4,514 & 0,728 \\
\hline & 35,11 & hyperoside & 315,6 & 9,161 & 0,578 \\
\hline & 35,616 & & 23,7 & 0,688 & 0,438 \\
\hline & 36,577 & & 9,8 & 0,284 & 1,534 \\
\hline & 36,843 & kaempferol & 37,9 & 1,100 & 0,815 \\
\hline & 37,799 & & 28,7 & 0,833 & 0,861 \\
\hline & 38,976 & & 76 & 2,206 & 1,702 \\
\hline & 40,144 & & 35,2 & 1,022 & 0,858 \\
\hline & 40,588 & & 21,7 & 0,630 & 0,613 \\
\hline & 41,531 & & 51,5 & 1,495 & 1,427 \\
\hline & 42,576 & & 290,5 & 8,433 & 0,859 \\
\hline & 43,101 & & 27,1 & 0,787 & 0,426 \\
\hline & 44,931 & luteolin & 63,3 & 1,837 & 0,551 \\
\hline & 46,294 & kaempferitrin & 143,9 & 4,177 & 0,562 \\
\hline & 48,763 & & 30,9 & 0,897 & 1,003 \\
\hline & 55,906 & orientin & 1026 & 29,782 & 0,507 \\
\hline & 60,993 & isoorientin & 238 & 6,909 & 0,653 \\
\hline
\end{tabular}

Table 3: The content of vitexin and total flavonoids content in terms of vitexin in PDE.

\begin{tabular}{cccc}
\hline Object & $\begin{array}{c}\text { Number of } \\
\text { compounds of } \\
\text { flavonoid nature }\end{array}$ & $\begin{array}{c}\text { Vitexin } \\
\text { content } \\
\left(\mathrm{X}_{\mathrm{av}} \pm \Delta \mathrm{X}\right), \%\end{array}$ & $\begin{array}{c}\text { Total flavonoids content } \\
\text { in terms of vitexin }\left(\mathrm{X}_{\mathrm{av}} \pm\right. \\
\Delta \mathrm{X}), \%\end{array}$ \\
\hline $\begin{array}{c}\text { P. incarnata } \\
\text { dry extract }\end{array}$ & 20 & $0,867 \pm 0,011$ & $3,762 \pm 0,049$ \\
\hline
\end{tabular}

N: 5-number of repeat tests; f: 4-number of degrees of freedom; P\%: $0.95-$ confidence figure; $\mathbf{t}(\mathbf{P}, \mathbf{f}): 2,78-$ Student's coefficient; $\mathbf{X}_{\mathrm{av}}$ : mean value; $\mathbf{\Delta X}$ : Confidence interval. between the phenolic compounds quantity and the pharmacological activity.

However, HPLC-UV plays an important role, especially in the qualitative and quantitative analysis of $P$. incarnata flavonoids. The suggested HPLC procedure offers the advantage of using widely available, low-costing analytical standards and can be used in pharmacopoeial analysis of $P$. incarnata medicinal plant materials and herbal drugs.

According to the literature it is clear that $P$. incarnata displays considerable quantitative and qualitative variability of flavonoids, that can be used as markers for herbal extracts. Whereas the BAS responsible for the $P$. incarnata therapeutic effects are yet to be found, herbal drugs should be produced with the approved $P$. incarnata vitexin chemotype until the pharmacological significance of differences in chemotype are found out.

\section{CONCLUSION}

In the course of HPLC-UV analysis, it was found that 20 compounds of flavonoid nature are presented in P. incarnata dry extract. 9 flavonoids have been identified: isovitexin, vitexin, rutoside, hyperoside, luteolin, kaempferol, kaempferitrin, orientin, and isoorientin. The content of vitexin is $0,867 \pm 0,011 \%$, total flavonoids content in terms of vitexin is $3,762 \pm 0,049 \%$.

The obtained data will be used for standardization of drugs produced from $P$. incarnata dry extract in the Russian Federation.

\section{ACKNOWLEDGEMENT}

Supported by the "Russian Academic Excellence Project 5-100".

\section{CONFLICT OF INTERESTS}

None.

\section{REFERENCES}

1. Miroddi M, Calapai G, Navarra M, Minciullo PL, Gangemi S. Passiflora incarnata L.:ethnopharmacology, clinical application, safety and evaluation of clinical trials. J Ethnopharmacol. 2013;150(3):791-804.

2. Wohlmuth $H$, Penman KG, Pearson T, Lehmann RP. Pharmacognosy and chemotypes of passionflower (Passiflora incarnata L.). Biol Pharm Bull. 2010;33(6):1015-8.

3. Duke JA, Ayensu ES. Medicinal plants of China. Algonac (Mich.): Reference publ. 1985;1-2:705

4. Patel SS, Saleem TM, Ravi V, Shrestha B, Verma NK, Gauthaman K Passiflora incarnata Linn:A phytopharmacological review. Int J Green Pharm. 2009;3(4):277-80.

5. Gavasheli NM, Eristavi LI, Moniava II. Oxycoumarins from Passiflora incarnata (Russian). Chem Nat Compd. 1973;4:552-552.

6. Duke JA. CRC handbook of medical herbs. Boca Raton (Fla.): CRC press;1986.

7. Raffaelli A, Moneti G, Mercati V, Toja E. Mass spectrometric characterization of flavonoids in extracts from Passiflora incarnata. J Chromatogr A. 1997;777(1):223-31.

8. Rahman K, Krenn L, Kopp B, Schubert-Zsilavecz M, Mayer KK, Kubelka W. Isoscoparin-2"-O-glucoside from Passiflora incarnata. Phytochemistry. 1997;45(5):1093-4.

9. Proliac A, Raynaud J. 2-O-Glucosyl-6-C-glucosylapigenin from P. incarnata L. (Passifloraceae). Pharmaceutica ACTA Helvetica. 1988;63:174-5.

10. Chimichi S, Mercati V, Moneti G, Raffaelli A, Toja E. Isolation and characterization of an unknown flavonoid in dry extracts from P. incarnata. Natural Product Letters. 1998;11:225-32.

11. Tolkachova NV, Logvinenko LA, Shevchuk OM. The active compound content in Passiflora incarnata L. and Passiflora caerulea L.in the Southern Coast of the Crimea. Bull of the State Nikita Botan Gard. 2017;123:77-83.

12. European pharmacopoeia. Edition 9.0. Council of Europe Strasbourg;2017.

13. German Pharmacopoeia. Deutsches Arzneibuch 2015 (DAB 2015), 2015.

14. French Pharmacopoeia (11th edition). Pharmacopée française ( Ph. fr.11ème édition);2012. 
15. British Pharmacopoeia (BP);2017.

16. British Herbal Pharmacopoeia (BHP). Exeter, U.K.:British Herbal Medicine Association;1996.

17. Pharmacopoeial monograph of Russian State Pharmacopoeia 42-2784-91. Passiflora herb- Passiflorae herba.

18. State Register of Medicines. The Russian Federation Ministry of Health. http:// grls.rosminzdrav.ru/grls.aspx.

19. Nechaeva NP. Homeopathic remedy for the treatment of alcohol dependence patent for invention of Russian federation. RUS 2151610 04.06.1999 [in Russian].

20. Dhawan K, Kumar S, Sharma A. Anxiolytic activity of aerial and underground parts of Passiflora incarnata. Fitoterapia.2001;72(8):922-6.

21. Aman U, Subhan F, Shahid M, Akbar S, Ahmad N, Ali G, et al. Passiflora incarnata attenuation of neuropathic allodynia and vulvodynia apropos GABAergic and opioidergic antinociceptive and behavioural mechanisms. BMC Complementary and Alternative Medicine. 2016:16(1):77.

22. Singh P, Singh D, Goel R. Phytoflavonoids:antiepileptics for the future. Int J Pharm Pharm Sci. 2014:6(8):51-66.
23. Souza V, Andrade F, Souza F, Macedo R. Analytical method by HPLC-DAD allows quantification of quercetin marker in standardized extract of Anadenanthera colubrina var. Cebil. Int J Pharm Pharm Sci. 2017;9(8):47-55.

24. Assessment report on Passiflora incarnata L., herba Based on Article 16d (1) Article $16 f$ and Article 16h of Directive 2001/83/EC as amended (traditional use) Final. Committee for Herbal Medicinal Products (HMPC) 25 March 2014. EMA HMPC/669738/2013. http://www.ema.europa.eu/docs/en_GB/document library/Herbal_-_HMPC_assessment_report/2014/06/WC500168964.pdf

25. Pereira CA, Yariwake JH, Lanças FM, Wauters JN, Tits M, Angenot L. A HPTLC densitometric determination of flavonoids from Passiflora alata, P. edulis, $P$ incarnata and P. caerulea and comparison with HPLC method. Phytochemica Analysis: An International Journal of Plant Chemical and Biochemical Techniques. 2004;15(4):241-8

26. Masteikova R, Bernatoniene J, Bernatoniene R, Saule V. Antiradical activities of the extract of Passiflora incarnata. Acta Pol Pharm. 2008;65(5):577-83.

27. Wohlmuth $H$, Penman KG, Pearson T, Lehmann RP. Pharmacognosy and chemotypes of passionflower (Passiflora incarnata L.). Biological and Pharmaceutical Bulletin. 2010:33(6):1015-18.

\section{GRAPHICAL ABSTRACT}

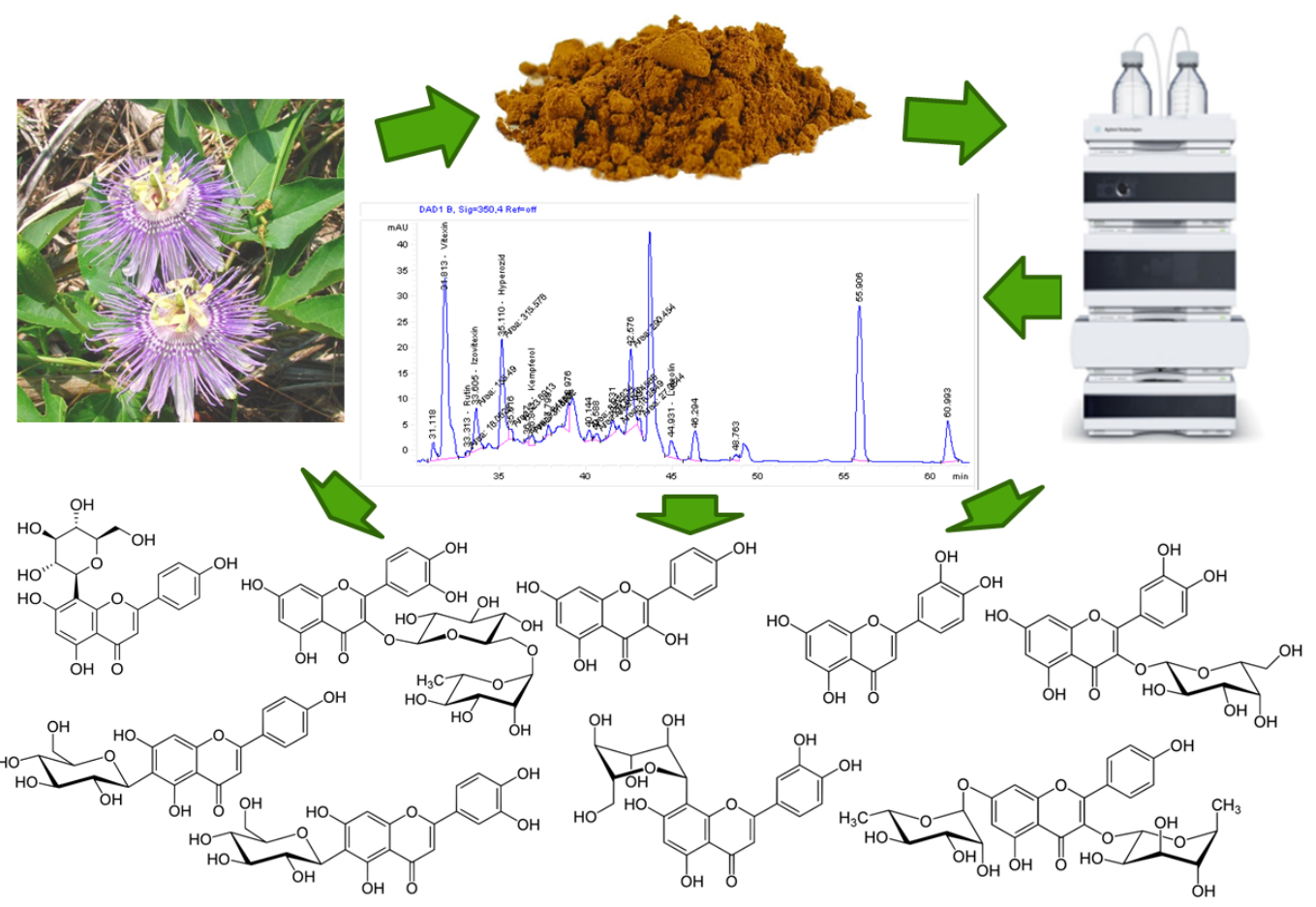

\section{ABOUT AUTHORS}

Guseinov Magomed Dzhamaludinovich, Deputy Director for Academic Affairs, Medical College named after Bashlarov; Research interests: pharmacognosy, sedative medicinal plant materials.

Bobkova Natalya Vladimirovna, Doctor of Pharmaceutical Sciences, Associate Professor, professor of Natural Science Department, Institute of Pharmacy, Sechenov University; Research interests: pharmacognostic study of complex medicinal herbal remedies, microscopic investigation of medicinal plant materials.

Svistunov Andrei Alekseevich, Corresponding Member of the Russian Academy of Sciences, Professor, Doctor of Medical Sciences, First Vice-Rector, Sechenov University; Research interests: history of pharmacy, hemostasis issues, principles of personalized pharmacotherapy

Tarasov Vadim Vladimirovich, Candidate of Pharmaceutical Sciences (Ph.D.), Head of the Department of Pharmacology, Director of Institute of Translational Medicine and Biotechnology, Sechenov University; Research interests: management and economics of pharmacy, pharmacology, sports, personalized medicine, pharmacotherapy, translational medicine. 
Bokov Dmitry Olegovich, Candidate of Pharmaceutical Sciences (Ph.D.), Associate Professor, Department of Pharmaceutical Natural Sciences, Department of Analytical, Physical and Colloid Chemistry, Institute of Pharmacy, Sechenov University; Laboratory of Food Chemistry, Federal Research Center for Nutrition, Biotechnology and Food Safety. Research interests: pharmacognosy, analytical chemistry, investigation of the composition and content of biologically active compounds in crude herbal drugs using modern instrumental methods of analysis (HPLC with RID, UV, MS-MS detection, GC-MS).

Sergunova Ekaterina Vyacheslavovna, Doctor of Pharmaceutical Sciences, Associate Professor, Professor of Department of Pharmaceutical Natural Sciences, Institute of Pharmacy, Sechenov University. Research interests: pharmacognosy, influence of conservation methods on the composition and content of biologically active substances in medicinal plant materials.

Kovaleva Tatyana Yurievna, Candidate of Pharmaceutical Sciences (Ph.D.), Associate Professor, Department of Pharmaceutical Natural Sciences, Institute of Pharmacy, Sechenov University. Research interests: pharmacognosy, standardization of urological (diuretic), anxiolytic, nootropic medicinal herbal products.

Cite this article: Guseinov MD, Bobkova NV, Svistunov AA, Tarasov VV, Bokov DO, Sergunova EV, et al. Flavonoids in Passiflora incarnata L. Dry Extract of Russian Origin. Pharmacog J. 2019;11(5):1143-7. 